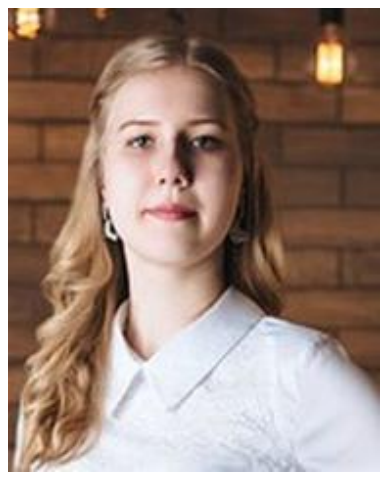

\section{О ВОЗМОЖНОСТЯХ ИСПОЛЬЗОВАНИЯ \\ НЕТРАДИЦИОННОГО РАСТИТЕЛЬНОГО СЫРЬЯ В ТЕХНОЛОГИИ ЗРАЗ ИЗ КАЛЬМАРА}

\author{
А.А. Качковская, студент, \\ e-mail: ankakachkovskaya@mail.ru \\ ФГБОУ ВО «Калининградский государственный \\ технический университет» \\ Н.Ю. Ключко, канд. техн. наук, доц., \\ e-mail: natalya.kluchko@klgtu.ru \\ ФГБОУ ВО «Калининградский государственный \\ технический университет»
}

Раскрывается потенциал нетрадиционного растительного сырья: листьев сныти обыкновенной, репы столовой в качестве обогащающих компонентов начинки для замороженных полуфабрикатов (зраз) из фарша кальмара.

Разработка поликомпонентной продукции направлена на устранение дефицита макрои микронутриентов, превалирующего фактора в формировании иммунитета. Экспериментально доказана сбалансированность изделий по витаминно-минеральному составу. Изучена роль питания в формировании иммунитета. Полученные данные об иммуномодулирующей направленности обогащенных изделий подкреплены теоретически.

Рассмотрены реологические свойства кальмарной фаршевой системы и возможность применения сухой моркови в качестве стабилизирующей добавки.

Проведены маркетинговые исследования рентабельности концепции производства продукции повышенной биологической ценности на территории Калининградской области.

Ключевые слова: зразы, полуфабрикаты, кальмар командорский, сныть, репа столовая, сухая морковная стружка, показатель пищевой сбалансированности, иммуномодулирующая активность, влагоудерживающая способность.

\title{
ВВЕДЕНИЕ
}

В качестве центральной проблемы исследований рассмотрены рост заболеваемости населения простудными сезонными заболеваниями и роль сбалансированного питания в формировании его иммунитета. Несмотря на то, что современная медицина активно борется с заболеваемостью острыми респираторными вирусными инфекциями (ОРВИ) методом ревакцинации, анализ статистики показывает недостаточную эффективность метода.

Как видно из данных по исследованию ПМГМУ им. И.М. Сеченова заболеваемости гриппом и ОРВИ, представленных на рис. 1 [1], заболеваемость, вызванная вирусными инфекциями, находится на постоянном уровне. Такая тенденция говорит нам о том, что вирусные штаммы подвержены постоянной мутации, из-за чего нет 100\%-ной вероятности формирования устойчивого иммунитета. Поэтому следует обратить внимание на дополнительные меры по укреплению иммунной системы извне.

Решением данной проблемы может стать коррекция рациона питания населения. 


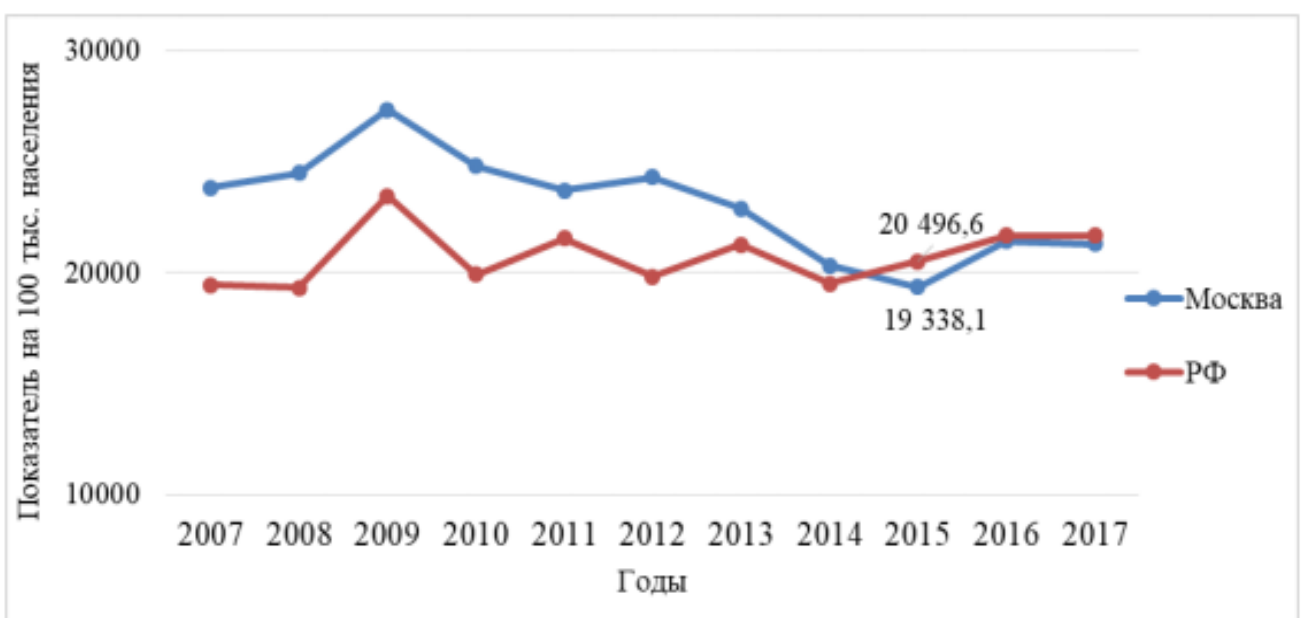

Рисунок 1 - Динамика заболеваемости ОРВИ населения РФ и г. Москвы за период 2007-2017 гг.

Снижение иммунитета в весенне-зимний период связано с недостаточным потреблением несезонной растительной пищи, провоцирующим дефицит макро- и микронутриентов, ответственных за его формирование.

При подборе основного сырья учитывались следующие факторы:

1) Высокое содержание аскорбиновой кислоты, витамина А и минеральных веществ, таких как: медь, марганец, железо, цинк, селен, выступающих в роли кофакторов синтеза иммунных тел: Т-лимфоцитов, макрофагов и интерферона. Влияние данных нутриентов на иммунитет научно доказано и освещено в статье для педиатрии от НИИ питания РАМН [2].

2) Иммунные тела имеют белковую природу происхождения, следовательно, конструируемые изделия должны отвечать требованию сбалансированности аминокислотного состава, играющего роль основного пластического материала в построении антител.

3) Также неоспоримо важным является уровень содержания клетчатки в качестве питательной среды для развития микробиотов кишечника. Швейцарскими учеными факультета биологии и медицины Лозаннского университета было доказано в исследовательской работе об иммуномодулирующей функции микробиотов кишечника [3], что естественная микрофлора синтезирует защитные антитела иммуноглобулины $\lg$ А и 70 \% всех лимфоцитов организма.

Таким образом, можно говорить о том, что массовые продукты питания должны играть роль не только энергетического источника, но и быть сбалансированными, полезными по составу.

\section{ОБЬЕКТ ИССЛЕДОВАНИЯ}

В качестве объекта были выбраны замороженные рубленые полуфабрикаты, которые имеют высокую популярность среди потребителей из-за быстроты доведения их до кулинарной готовности, но, тем не менее, их ингредиентный состав не сбалансирован и не отвечает требованиям новых тенденций в пищевой биотехнологии в рамках сферы производства лечебно-профилактического питания.

Несмотря на востребованность, рыбный ассортимент рубленых полуфабрикатов занимает незначительную долю на рынке потребления: всего 2 \% от общего производства.

Требуется расширение ассортимента рыбной полуфабрикатной продукции.

В качестве основного компонента рецептуры выбрано диетическое кальмарное сырье (122 ккал на 100 г продукта). Кальмары в сравнении с животным сырьем не содержат холестерина и при этом ценны с точки зрения полноценного белкового состава, к тому же в них повышено содержание полиненасыщенных жирных кислот, полезных в профилактике атеросклероза. Употребление 100 г кальмаров покрывает суточную потребность в йоде, нормализующем работу эндокринной системы, и селене, защитном пищевом веществе, отвечающем за выведение токсинов. 
По теории сбалансированного питания для достижения баланса нутриентов рекомендуется сочетать животное и растительное сырье.

Дополняющим состав сырьем были выбраны: листья сныти обыкновенной и корнеплоды репы столовой.

Сныть обыкновенная, многолетнее травянистое растение, необоснованно причисляется на территории РФ к сорняковым дикоросам. Ценность ее состава как пищевого сырья рассмотрена в научно-исследовательской работе [4].

Второй обогащающий компонент начинки зраз - репа столовая тоже является ценным сырьем с нереализованным потенциалом. На рубеже 17 века этот питательный корнеплод с ценными биологически активными веществами затенил новомодный крахмалистый картофель.

\section{ЦЕЛИ И ЗАДАЧИ ИССЛЕДОВАНИЯ}

Цель работы заключается в совершенствовании технологии поликомпонентных замороженных полуфабрикатных изделий из фарша кальмара с повышенной биологической ценностью иммунологической направленности.

Для достижения поставленной цели были решены следующие задачи:

1) Обоснование рациональности использования в технологии нетрадиционного растительного сырья в качестве обогащающего компонента.

2) Оптимизация рецептуры изделий методом математического моделирования.

3) Изучение влияния стабилизирующей добавки моркови на реологические свойства фаршевой системы эталонного образца.

\section{РЕЗУЛЬТАТЫ ИССЛЕДОВАНИЯ}

Обоснование рациональности подбора сырья для обогащения осуществлялось методом теоретического расчета пищевой сбалансированности. Был произведен сравнительный расчет ППСБ двух рецептур зраз с обогащением (№ 2) и без (№ 1).

По расчетам пищевой сбалансированности получены следующие данные, табл. 1.

Таблица 1 - ППСБ полуфабрикатов

\begin{tabular}{|c|c|c|c|c|c|c|c|c|c|c|}
\hline Объект & $\begin{array}{l}\dot{5} \\
\dot{\Delta} \\
\dot{\Delta} \\
\dot{\Xi}\end{array}$ & $\begin{array}{l}\dot{E} \\
\dot{U} \\
\dot{5} \\
\dot{5}\end{array}$ & 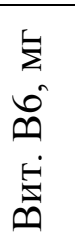 & $\begin{array}{l}\stackrel{0}{\infty} \\
\dot{\Xi} \\
\dot{D}\end{array}$ & $\stackrel{5}{n}$ & 氖 & 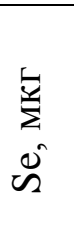 & $\begin{array}{l}\sum \\
\sum \\
\sum \hat{D}\end{array}$ & $\begin{array}{l}E \\
\dot{E} \\
0 \pm\end{array}$ & $\begin{array}{l}\xi \\
\dot{N} \\
\dot{N}\end{array}$ \\
\hline 1 & 2 & 3 & 4 & 5 & 6 & 7 & 8 & 9 & 10 & 11 \\
\hline $\begin{array}{c}\text { Норма суточ- } \\
\text { ного потереб- } \\
\text { ления по МР } \\
2.3 .1 .2432-08 \\
{[5](\mathrm{X})}\end{array}$ & 900 & 90 & 2 & 3 & 150 & 1000 & 55 & 400 & 18 & 12 \\
\hline $\begin{array}{c}\text { Содержание } \\
\text { по рецептуре } \\
\text { №1 }\left(\mathrm{Y}_{1}\right)\end{array}$ & 47 & 2,02 & 0,2 & 1,3 & 303 & 1571 & 49 & 92,8 & 1 & 1,9 \\
\hline $\begin{array}{c}\Pi \Pi \mathrm{CБ}_{1}=\frac{Y_{1}}{X} * \\
100\end{array}$ & 5,2 & 2,2 & 12 & 46 & 202 & 157 & 90 & 23,2 & 8 & 17 \\
\hline
\end{tabular}


Окончание таблицы 1

\begin{tabular}{|l|c|c|c|c|c|c|c|c|c|c|}
\hline \multicolumn{1}{|c|}{1} & 2 & 3 & 4 & 5 & 6 & 7 & 8 & 9 & 10 & 11 \\
\hline $\begin{array}{l}\text { Содержание } \\
\text { по рецептуре } \\
\text { № 2 }\left(\mathrm{Y}_{2}\right)\end{array}$ & 321 & 15,08 & 0,4 & 1,3 & 150 & 785,6 & 50,4 & 166 & 35,4 & 2,2 \\
\hline $\begin{array}{l}\text { ППСБ } \\
100\end{array}=\frac{Y_{2}}{X} *$ & 35,7 & 16,8 & 20 & 43,3 & 100 & 158 & 91,6 & 41,4 & 197 & 18 \\
\hline
\end{tabular}

Обогащенные полуфабрикаты по перечисленным функциональным ингредиентам удовлетворяют более 15 \% суточной потребности, их можно причислить к продукции иммунологического действия с эффектом витаминно-минерального премикса.

В сырье йодометрическим методом по ГОСТ 7047-55 было определено содержание основного регламентируемого иммунологического компонента - витамина С, табл. 2.

Таблица 2 - Содержание витамина С в обогащающих ингредиентах

\begin{tabular}{|l|c|}
\hline \multicolumn{1}{|c|}{ Объект исследования } & $\begin{array}{c}\text { Уровень содержания аскорбиновой кислоты, } \\
\text { мг\% }\end{array}$ \\
\hline Сухие листья сныти обыкновенной & 20,4 \\
\hline Измельченные корнеплоды репы столовой & 40,5 \\
\hline Сухая морковная стружка & 14,2 \\
\hline
\end{tabular}

Определили водосвязывающую способность сухой моркови, табл. 3.

Талица 3 - Определение водосвязывающей способности стабилизирующего компонента

\begin{tabular}{|c|c|}
\hline Объект исследования & $\begin{array}{c}\text { Водосвязывающая способность, } \\
\text { мл/г, навески }\end{array}$ \\
\hline Сухая морковная стружка & 5,42 \\
\hline
\end{tabular}

Произвели оптимизацию рецептурного состава зраз методом математического моделирования. Получили следующие значения параметров оптимизации, отвечающих за показатели качества изделий по реологическим и органолептическим параметрам: $\mathrm{X} 1=9,0$ \%, содержания в фарше моркови; X2=3, 07 мм, диаметр отверстий волчка. Графическое изображение математической модели представлено на рис. 2.

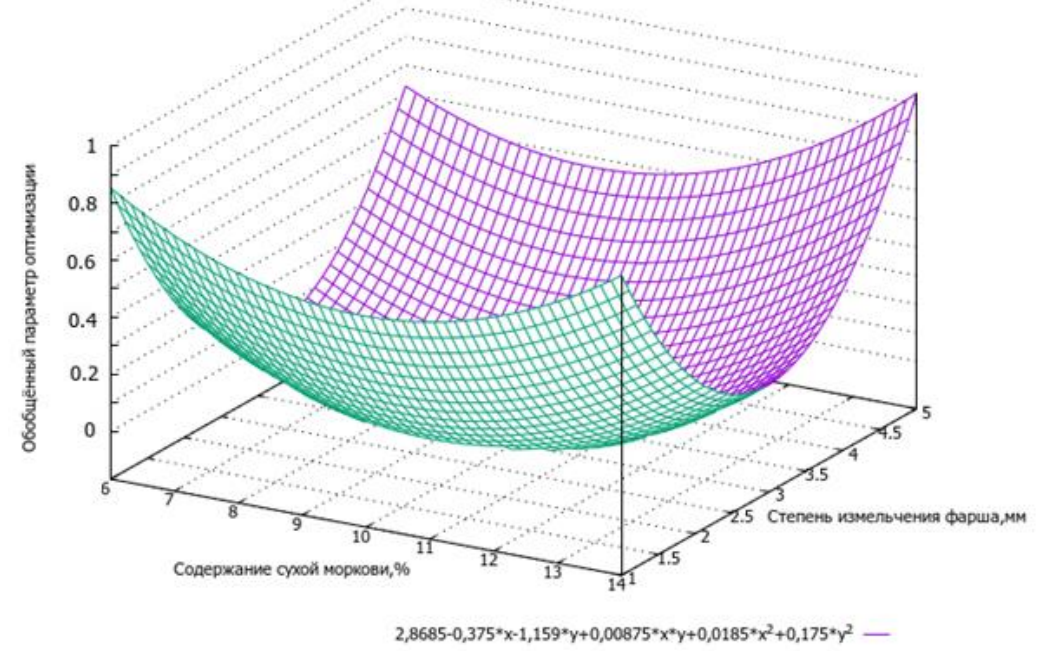


Рисунок 2 - Геометрическая модель оптимизации рецептуры конструируемого полуфабриката

Изучили эффективность стабилизирующих свойств сухой моркови по сравнительному анализу функционально-технологических свойств (ФТС) экспериментальных образцов фаршевой системы, табл. 4.

Как видно по данным табл. 3, морковь имеет высокий показатель водосвязывания. В эксперименте с фаршевыми системами выяснили, что ее набухание снижает потери тканевого сока при термообработке до $0 \%$, табл. 4.

Наилучшие результаты ВУС имеет образец, измельченный на волчке с диаметром отверстий 3 мм, и с введением 9 \%-ной стабилизирующей добавки сухой моркови.

Таблица 4 - Исследования ФТС экспериментальных фаршевых систем

\begin{tabular}{|c|c|c|c|c|c|}
\hline $\begin{array}{c}\text { Наименование } \\
\text { образца }\end{array}$ & ВУС, $\%$ & $\begin{array}{l}\text { Условная } \\
\text { ВУС, \% }\end{array}$ & $\begin{array}{l}\text { Потери } \\
\text { термооб }\end{array}$ & $\begin{array}{l}\text { код при } \\
\text { отке, \% }\end{array}$ & $\begin{array}{c}\text { Массовая } \\
\text { доля влаги, } \\
\%\end{array}$ \\
\hline \multicolumn{6}{|c|}{ Влияние степени измельчения фарша и введения 9\%-ной добавки моркови } \\
\hline $\mathrm{D}=3$ мм без моркови & 73,7 & 43,5 & 8,73 & 91,27 & 78,5 \\
\hline $\mathrm{D}=3$ мм с морковью & 76,3 & 15,6 & 0 & 102,7 & 79,4 \\
\hline $\mathrm{D}=5$ мм с морковью & 60,09 & 44,01 & 12,08 & 87,92 & 79,8 \\
\hline $\mathrm{D}=5$ мм без моркови & 64,4 & 11,4 & 0 & 102,4 & 73,7 \\
\hline
\end{tabular}

В эталонном образце изделия определили содержание сырой клетчатки, табл. 5.

Таблица 5 - Содержание клетчатки в обогащенных полуфабрикатах

\begin{tabular}{|c|c|}
\hline Показатель качества & Содержание в 100 г продукта, \% \\
\hline Массовая доля сырой клетчатки & 12,6 \\
\hline
\end{tabular}

Как уже было определено выше, в готовых конструируемых изделиях прогнозируется высокое содержание витамина $\mathrm{C}$, норма суточного потребления которого по методическим рекомендациям МР 2.3.1.2432-08 от ГУ НИИ питания РАМН для взрослого человека составляет 90 мг [5].

Известен факт, что большинство витаминов разрушается в условиях жестких режимов термообработки, поэтому было определено содержание данного витамина в образцах различной степени кулинарной подготовки, табл. 6.

Таблица 6 - Определение содержания аскорбиновой кислоты в полуфабрикатах

\begin{tabular}{|l|c|c|c|}
\hline \multicolumn{1}{|c|}{ Вид термообработки } & $\begin{array}{c}\text { Количество } \\
\text { витамина С, } \\
\text { мг/100 г } \\
\text { продукта }\end{array}$ & $\begin{array}{c}\text { Количество вита- } \\
\text { мина С в рекомен- } \\
\text { дуемой порции } \\
\text { (двух единицах из- } \\
\text { делия), мг/120 г } \\
\text { продукции }\end{array}$ & $\begin{array}{c}\text { Процентное соот- } \\
\text { ношение от РСП, \% }\end{array}$ \\
\hline 1 & 2 & 3 & 4 \\
\hline $\begin{array}{l}\text { Полуфабрикаты, жареные в } \\
\text { растительном масле. } \\
\begin{array}{l}\text { Режим: } \tau=3 \text { минуты, } \mathrm{t}=140- \\
150{ }^{\circ} \mathrm{C}\end{array}\end{array} \quad 6,6$ & 7,92 & 9 \\
\hline
\end{tabular}


Окончание таблицы 6

\begin{tabular}{|l|c|c|c|}
\hline \multicolumn{1}{|c|}{1} & 2 & 3 & 4 \\
\hline $\begin{array}{l}\text { Приготовление на пару. } \\
\begin{array}{l}\text { Режим: } \tau=10 \text { минут, } \mathrm{t}=180- \\
200^{\circ} \mathrm{C}\end{array}\end{array} \quad 18,3$ & 21,96 & 24 \\
\hline Сырые полуфабрикаты & 20 & 24 & 27 \\
\hline
\end{tabular}

По данным табл. 6, менее губительной по отношению к витамину С можно назвать паровую термообработку полуфабрикатов; данный способ доведения до кулинарной готовности предлагается к внесению в перечень рекомендаций от производителя.

По результатам социологического опроса: "Маркетинговое исследование потребительских предпочтений в сфере здорового питания” было выяснено следующее.

Потребители положительно относятся к обогащению нетрадиционным растительным сырьем и готовы включить их в свой рацион питания, рис. 3.
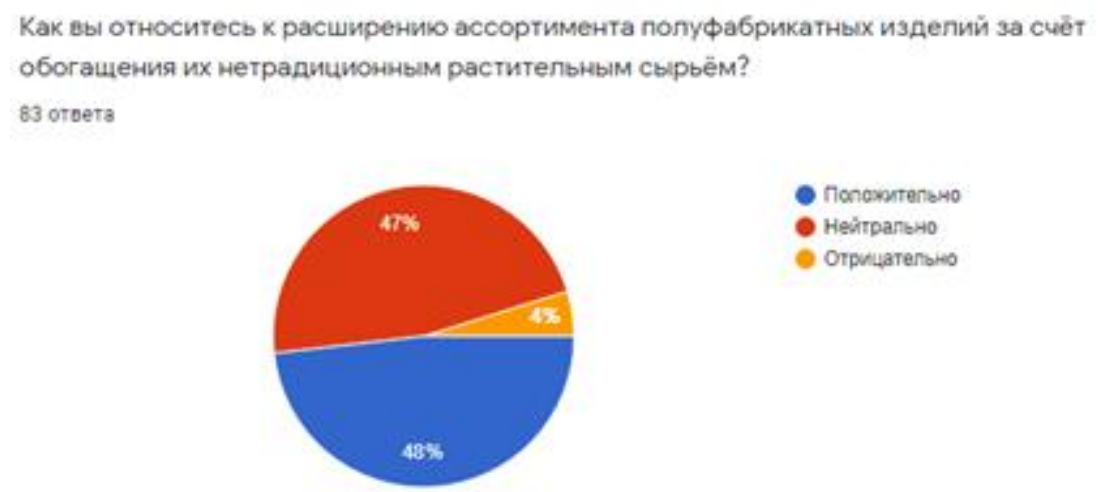

Рисунок 3 - Диаграмма отношения опрашиваемых к концепции обогащения

Большинство потребителей знают о пользе нетрадиционного растительного сырья, и, тем не менее, малая доля (20,5\%) респондентов включает их в свой рацион питания (рис. 4).

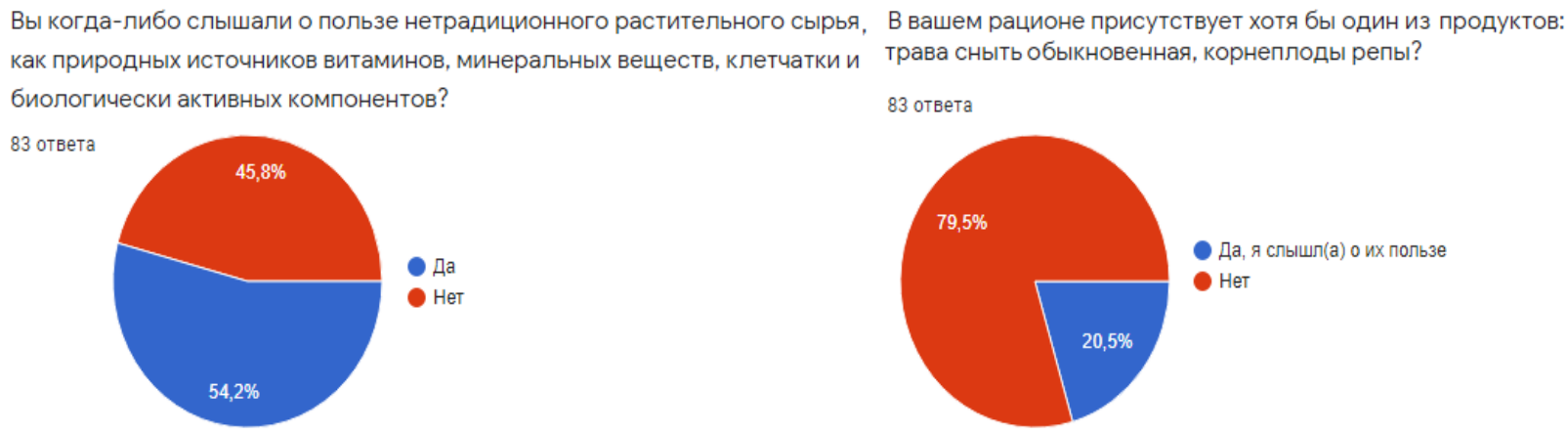

Рисунок 4 - Диаграммы эффективности информирования потребителей

Эти показатели могут свидетельствовать о необоснованном отказе на территории РФ от культивирования и разработки сырья: сныти обыкновенной и репы. Данные ценные сырьевые источники нуждаются в расширении масштабов реализации их потенциала. Концепция совершенствования технологий замороженных полуфабрикатов с повышенной пищевой ценностью актуальна. 


\title{
ЗАКЛЮЧЕНИЕ
}

Выявлена причина ослабления иммунитета в весенне-зимний период. Несбалансированный рацион питания является базовой причиной развития витаминно-минерального дисбаланса, приводящего к снижению эффективности действия иммунного барьера человеческого организма.

Цель научно-исследовательской работы достигнута, разработана рецептура иммунопрофилактической обогащенной продукция из фарша кальмара для всех групп населения. Разработка дает возможность расширения ассортимента рыбных полуфабрикатов и по результатам проведения социологического опроса и анализа рынка потребления имеет потенциал в реализации на территории Калининградской области.

\section{СПИСОК ЛИТЕРАТУРЫ}

1. Жигарловский, Б.А. Эпидемиологическая характеристика и оптимизация эпидемиологического надзора за гриппом и ОРВИ: дис...канд. мед. наук: 14.02 .02 / Жигарловский Бронислав Андреевич; ПМГМУ им. И.М. Сеченова. - Москва, 2019. - 256 с.

2. Моносова, О.Ю. Витамины, микро- и макронутриенты и их влияние на иммунную систему / О. Ю. Моносова, К. Г. Шарапова // Эффективная фармакотерапия. Педиатрия. 2010 . - № 2. - C. 6-11.

3. Aure' lien Trompette. Dietary Fiber Confers Protection against Flu by Shaping Ly6c- Patrolling Monocyte Hematopoiesis and CD8+ T Cell Metabolism/ Aure' lien Trompette, Eva S. Gollwitzer, Ce' line Pattaroni, Lluis Fajas, Laurent P. Nicod, Benjamin J. Marsland // Immunity . 2005. - №48 (5). - C. 992-1005.

4. Шишкина, Н.В. Пищевая ценность сныти обыкновенной Aegopodium podagraria L. (Арiaceae) и ее использование в технологии продуктов функционального назначения: дис...канд. техн. наук: 05.18.01 / Шишкина Наталья Владимировна; РГАУ МСХА им. К.А. Тимирязева. - Москва, 2010. - 245 с.

5. Нормы физиологических потребностей в энергии и пищевых веществах для различных групп населения Российской Федерации. Методические рекомендации МР 2.3.1.2432-08 / В.А. Тутельян [и др.]. - Москва, 2009. - 36 с.

\section{ABOUT THE PROSPECTS FOR USING NON-TRADITIONAL PLANT RAW MATERIALS IN THE TECHNOLOGY OF SQUID MINCED MEAT SEMI FINISHED PRODACTS}

\author{
A.A. Kachkovskaya, student, \\ e-mail: ankakachkovskaya@mail.ru \\ Kaliningrad State Technical University \\ N.Yu. Klyuchko, PhD, Associate Professor, \\ e-mail: natalya.kluchko@klgtu.ru \\ Kaliningrad State Technical University
}

The work reveals the potential of unconventional plant raw materials: leaves of Aegopodium podagraria L. and turnip as an enriching component of the filling for frozen semi-finished products from squid minced meat. The development of multicomponent products is aimed at eliminating the deficiency of macro-micronutrients, the prevailing factor in the formation of immunity. The balance of products in terms of vitamin and mineral composition has been experimentally proven.

The role of nutrition in the formation of immunity has been examined. The obtained data on the immunomodulatory action of enriched products are supported theoretically. The rheological 
properties of the squid mince system and the possibility of using dry carrots as a stabilizing additive are considered. Marketing research of the profitability of the concept of production of products of increased biological value in the territory of the Kaliningrad region has been carried out.

Key words: Severe acute respiratory syndrome (SARS), Aegopodium podagraria, turnip Brassica rapa, dry carrots, squid - Berryteuthis magister, semi-finished products, Index of nutritional balance, immunomodulatory activity, water-holding capacity. 